\title{
CHILE. ACCESO A LA FICHA CLÍNICA PARA INVESTIGACIÓN CIENTÍFICA
}

\section{CHILE: CLINICAL DATA ACCESS FOR SCIENTIFIC RESEARCH}

\author{
Paulina Ramos Vergara* \\ Angela Arenas Massa ${ }^{*}$
}

\section{INTRODUCCIÓN}

La dignidad de la persona humana es el valor absoluto que justifica los derechos fundamentales, ya que su afirmación no solo constituye una garantía de tipo negativo que protege a las personas contra vejámenes y ofensas de todo tipo, sino que debe también afirmar positivamente a través de los derechos el pleno desarrollo de cada ser humano y de todos los seres humanos ${ }^{1}$.

Además, la dignidad es el principio inspirador de la Ley $\mathrm{N}^{\circ} 20.584$, que regula los derechos y deberes que las personas tienen en relación con acciones vinculadas a su atención en salud. Precisamente en el Mensaje se consigna "La dignidad inherente

\footnotetext{
Licenciada en Ciencias Jurídicas y Sociales, Universidad de Chile. Doctora en Derecho, Pontificia Universidad Católica, Chile. Profesora Asistente Centro de Bioética, Facultad de Medicina Pontificia Universidad Católica. Alameda No 340, Santiago de Chile. Correo: pramosv@med.puc.cl. Teléfono contacto: (2) 23546995.

" Licenciada en Ciencias Jurídicas y Sociales, Universidad Austral de Chile. Doctora en Bioética, Athenaeum Pontificium Regina Apostolorum, Italia. Profesora Asistente Centro de Bioética, Facultad de Medicina Pontificia Universidad Católica. Alameda No 340, Santiago de Chile. Correo: aarenasm@med. puc.cl. Teléfono contacto: (2) 23546995.

1 Nogueira, Humberto (2009): "Los derechos económicos, sociales y culturales como derechos fundamentales efectivos en el Constitucionalismo Democrático Latinoamericano", Revista Estudios Constitucionales - Universidad de Talca, vol. No 2: pp. 143-205.
}

a la condición humana como fuente y explicación de los derechos..." y agrega "Asi el valor especial y único de cada miembro de nuestra sociedad, constituye a las personas en el fin de toda norma y estructura social"2.

Entre los derechos inherentes a toda persona humana destaca el derecho a la privacidad -art. 19 N4- Constitución Política de la República de Chile, en adelante CPR, el cual forma parte de los derechos de la personalidad, junto con el derecho a la vida, derecho de nacer, a la integridad física y síquica, a fundar una familia, a la inviolabilidad del hogar y de las comunicaciones ${ }^{3}$. Es un derecho relativamente nuevo en la historia constitucional nacional ${ }^{4}$.

2 Boletín No 4398, Proyecto de Ley que regula los derechos y deberes que las personas tienen en relación con acciones vinculadas con salud. Cámara de Diputados, 20 de julio de 2007. p. 38 señala: "En relación al principio de la dignidad de las personas, hace presente la necesidad de que los sistemas de salud públicos y privados respeten permanentemente los derechos humanos, sobre todo en situaciones de necesidad, como ocurre cuando se solicita atención médica, a la vez que se hace cargo de la crítica formulada respecto de la deshumanización en las relaciones entre los actores de los sistemas de salud y en el trato que reciben los pacientes".

3 Aldunate, Eduardo (2008): Derechos fundamentales (Santiago, Editorial LegalPublishing). 30 pp.

4 Boletín No 896-07, Protección civil a la vida privada. Senado, 5 de enero de 1993. p.4 señala: "Sometemos a consideración del Senado un proyecto de ley que viene a llenar un vacío manifiesto en nuestro ordenamiento jurídico y cuyo propósito es dar una adecuada protección al derecho a la privacidad de las 
El sistema jurídico debe garantizar a toda persona su privacidad, la que comprende todos aquellos aspectos de la vida que la persona no desea sean conocidos por los otros sin su consentimiento. Uno de esos ámbitos es la confidencialidad de la información de salud, reconocida por el legislador en la Ley $\mathrm{N}^{\circ} 20.584$ como principio inspirador consagrado en la historia fidedigna y regulado específicamente en los artículos 5 letra c), 12 y $13^{5}$.

El secreto profesional, por otra parte, está configurado como una de las formas de proteger la confidencialidad de la relación médico-paciente garantizando a este último, que la información privada entregada en un ámbito profesional y de confianza

personas, en el ámbito del Derecho Civil, ante eventuales intromisiones ilegítimas... Para este efecto hemos tomado como parámetros orientadores los principales criterios esbozados por el derecho comparado de las naciones más avanzadas; los diversos convenios, pactos y trabajos suscritos por la comunidad internacional en materia de derechos humanos, civiles y políticos, tales como la Declaración Universal de Derechos Humanos, de 1948; la Declaración Americana de los Derechos y Deberes del Hombre, de 1949, el Pacto Internacional de Derechos Civiles y Políticos, de 1966 y, la Convención Americana sobre Derechos humanos, de 1969, y, el mandato constitucional establecido en los artículos $5^{\circ}$ y $19^{\circ}$ números 4 y 5 , de nuestra Ley Fundamental".

${ }^{5}$ Ley $\mathrm{N}^{\circ}$ 20.584, Sobre derechos y deberes de las personas que las personas tienen en relación con acciones vinculadas con salud. Diario Oficial, 24 de abril del 2012. El encabezado de su artículo 5o consagra el derecho de las personas a recibir un trato digno y respetuoso en todo momento $\mathrm{y}$, concreta extensivamente este derecho en su letra c), señalando que los prestadores deberán respetar y proteger la vida privada y la honra de la persona durante su atención de salud; en cuanto valores jurídicos, dignidad y vida privada mantienen cohesión recíproca."

Por su parte, los artículos 12 y 13 de la Ley en comento, se ubican bajo un epígrafe específico titulado: Párrafo $5^{\circ}$ De la reserva de la información contenida en la ficha clínica. -alianza terapéutica-, no será entregada a terceros.

El derecho a la intimidad y confidencialidad de la información contenida en la ficha clínica, el derecho de acceso a dichos datos, el deber de secreto y el deber de custodia están interrelacionados. Estos derechos personalísimos obligan al Estado a través de sus diferentes organismos y, a los particulares entre esos las instituciones de salud, farmacéuticas, centros de investigación, personal sanitario y demás personas.

Todo esto en base a un ordenamiento jurídico coherente en el que el centro se ubica el nomen dignitatem. Quien en lo referente a sus atenciones de salud es un sujeto vulnerable, y a su vez titular pleno de derechos exigibles al Estado, a los prestadores de salud institucionales e individuales y a la sociedad toda.

Por otra parte, la CPR consagra como uno de los valores centrales de la institucionalidad nacional el "Bien Común” y lo define de tal forma, que todos los integrantes de la comunidad nacional, deben aportar a este a través de diferentes instancias. En materia de ficha clínica las restricciones al acceso a la información que ella contiene ceden mitigadas en favor del bien común cuando se ha justificado por salud pública.

\section{LA FICHA CLIINICA. DEFINICIÓN Y CARACTERÍSTICAS}

\subsection{Definición}

La definición de ficha clínica en la historia de la Ley $\mathrm{N}^{\circ} 20.584$ sobre derechos y deberes que las personas tienen en relación con acciones vinculadas a su atención en salud ha dado lugar a varias propuestas con diferentes alcances. A modo ejemplar, se presentan las siguientes: 
1. a. En el texto original que acompaña el mensaje del Ejecutivo, figura la siguiente:

"Artículo $12^{\circ}$. La ficha clínica es el instrumento en que se registra la historia médica de una persona.

Toda la información que surja, tanto de la ficha clínica como de los estudios y demás documentos donde se registren procedimientos y tratamientos a los que fueron sometidas las personas, será considerada como dato sensible, de conformidad a lo dispuesto en el artículo $2^{\circ}$ letra g) de la Ley $\mathrm{N}^{\circ}$ 19.628.)" ${ }^{\prime 6}$.

1. b. En el Segundo Informe de la Comisión de Salud de la Cámara de Diputados se propone la siguiente definición:

"La ficha clínica es el instrumento en el que se registra la historia clínica de una persona. Podrá configurarse de manera electrónica, en papel o en cualquier otro soporte, siempre que asegure la conservación y adecuada confidencialidad de la información en ella contenida”"

Mediante esta indicación los Parlamentarios pretendían aclarar las dudas que se suscitaron durante el debate, en cuanto al alcance del término "instrumento" utilizado para definir la ficha clínica. En ese contexto, si bien se tiene en consideración la amplitud de este último, sus autores recogieron las opiniones de algunos diputados que fueron partidarios de especificar en la norma que en

\footnotetext{
6 Boletín No 4398-11, Proyecto de Ley que regula los derechos y deberes que las personas tienen en relación con acciones vinculadas con salud. Cámara de Diputados, 26 de julio de 2006. p. 23.

7 Boletín No 4398-11. Proyecto de Ley que regula los derechos y deberes que las personas tienen en relación con acciones vinculadas con salud. Cámara de Diputados, 14 de octubre de 2008. p. 176
}

dicho término están comprendidos tanto los documentos que tienen existencia material como los archivos electrónicos, en atención a que la evolución de la tecnología ha apuntado al uso de mecanismos electrónicos para el resguardo de la información.

1. c. La definición finalmente acogida por el Legislador ha quedado plasmada en el artículo 12 de la Ley $N^{\circ} 20.584$ y el artículo 2 del Reglamento sobre Fichas Clínicas $N^{\circ} 41 / 2012$. La Ley define:

"Instrumento obligatorio en el que se registra el conjunto de antecedentes relativos a las diferentes áreas relacionadas con la salud de las personas, que tiene como finalidad la integración de la información necesaria en el proceso asistencial de cada paciente. Podrá configurarse de manera electrónica, en papel o en cualquier otro soporte, siempre que los registros sean completos y se asegure el oportuno acceso, conservación y confidencialidad de los datos, así como la autenticidad de su contenido y de los cambios efectuados en ella".

Por su parte, el Reglamento mencionado, en el artículo $2^{8}$, dispone:

"Ficha clínica es el instrumento obligatorio en que se registra el conjunto de antecedentes relativos a las diferentes áreas relacionadas con la salud de una persona, que cumple la finalidad de mantener integrada la información necesaria para el otorgamiento de atenciones de salud al paciente.

Las fichas clínicas podrán llevarse en soporte de papel, electrónico, u otro y su

8 Reglamento No 41/2012, sobre Fichas Clínicas. Diario Oficial, 15 de diciembre del 2012. Artículo 2. 
contenido se registrará por el profesional que efectúa la prestación de salud, en el acto de otorgarla o inmediatamente después de ello.

La información contenida en las fichas clínicas será considerada dato sensible, de conformidad con lo establecido en el artículo $2^{\circ}$ letra g) de la Ley $\mathrm{N}^{\circ} 19.628^{\prime}$.

\subsection{Características de la Ficha Clínica}

a. Claridad: el contenido de la ficha clínica debe ser comprensible a personas no expertas, como por lo general son los pacientes?

b. Veracidad: aquello consignado en el instrumento debe estar conforme a lo objetivamente constatado; reflejando fidedignamente la naturaleza y evolución de la enfermedad del paciente. Sin perjuicio de las anotaciones subjetivas del tratante.

c. Sistematicidad: del registro de la información que permita el cometido del instrumento a lo largo de la historia clínica del paciente ${ }^{10}$.

d. Resguardo: procurar con particular esmero el cuidado de la información recavada y generada en la atención de salud. En bioderecho e investigación científica, íntimamente relacionado al resguardo de la ficha clínica se encuentra el principio de precaución ${ }^{11}$.

\footnotetext{
9 Reglamento No 41/2012, sobre Fichas Clínicas. Diario Oficial, 15 de diciembre del 2012. Artículo 5.

10 Reglamento No 41/2012, sobre Fichas Clínicas. Diario Oficial, 15 de diciembre del 2012. Artículo 6.

11 Petrini, Carlo (2002): Bioetica, ambiente, rischio (Roma, Ateneo Pontificio Regina Apostolorum). El principio de precaución consiste en orientar la gestión de los riesgos potencialmente graves ante situaciones de incertidumbre científica sin esperar los resultados de la investigación. 53 pp.

Ello no es fácil de gestionar en política pública sanitaria precisamente porque muchas veces se cuenta con
}

e. Pertinencia: procedencia de la información reportada en la ficha con los requerimientos de la misma.

f. Completa: incorporar en la ficha clínica todos los elementos que la conforman ${ }^{12}$.

g. Oportuna: la información es registrada en forma concomitante a las causas que la generan ${ }^{13}$.

\section{TIPOS DE DATOS CONTENIDOS EN LA FICHA CLIINICA}

3.1. Dato de carácter personal: el relativo a cualquier información concerniente a personas naturales identificadas o identificables ${ }^{14}$; a saber, nombre, nacionalidad, domicilio, estado civil.

3.2. Dato de carácter sensible: aquellos datos personales que se refieren a las características físicas o morales de las personas o a hechos o circunstancias de su vida privada o intimidad, tales como los hábitos personales, el origen racial, las ideologías y opiniones políticas, las creencias y convicciones religiosas, los estados de salud físicos o psíquicos y la vida sexual ${ }^{15}$.

datos contenidos en las fichas clínicas que poseen carácter incierto y no conclusivo, pero que no obstante, sirven como insumos de partida para la investigación científica.

Reglamento No 41/2012, sobre Fichas Clínicas. Diario Oficial, 15 de diciembre del 2012. Artículos 8 y 9.

12 Reglamento No 41/2012, sobre Fichas Clínicas. Diario Oficial, 15 de diciembre del 2012. Artículos 3 у 6 .

13 Reglamento No 41/2012, sobre Fichas Clínicas. Diario Oficial, 15 de diciembre del 2012. Artículo 7.

${ }^{14}$ Ley $\mathrm{N}^{\circ} 19.628$, Protección a la vida privada. Diario Oficial, 28 de agosto de 1999. Artículo 2 letra f).

15 Ley N ${ }^{\circ} 19.628$, Protección a la vida privada. Diario Oficial, 28 de agosto de 1999. Artículo 2 letra g). 
Los datos contenidos en la ficha clínica, son eminentemente datos de carácter sensible; según el tenor literal de la legislación que protege la vida privada (específicamente artículo 2 letra g) de la Ley $\mathrm{N}^{\circ}$ 19.628), la que además ha sido reforzada por vía interpretiva de la Contraloría General de la República, en su Dictamen No 26.155 de fecha 7 mayo de $2012^{16}$. A mayor abundamiento y en sentido circular, este Dictamen es coetáneo a la publicación

16 Dictamen Contraloría General de la República No 26.155, 7 de mayo de 2012, Sobre remisión de fichas clínicas a las comisiones de Medicina Preventiva e Invalidez,. Disponible en: http://www.contraloria. cl/LegisJuri/DictamenesGeneralesMunicipales.nsf/ FrameSetConsultaWebAnonima [fecha consulta: 1 de marzo de 2013].

Párrafos 7 a 10:

"Señalado lo anterior, conviene hacer presente que el artículo $2^{\circ}$, letras f) y g), de la ley $\mathrm{N}^{\circ} 19.628$, sobre Protección de la Vida Privada, distingue entre datos de carácter personal o datos personales y datos sensibles, indicando que los primeros son aquellos relativos a cualquier información concerniente a personas naturales, identificadas o identificables, en tanto que los últimos son aquellos datos personales que se refieren a las características físicas o morales de las personas o a hechos o circunstancias de su vida privada o intimidad, tales como, en lo que interesa, los referentes a su estado de salud física o psíquica.

Enseguida, el artículo 20 de la citada normativa previene que el tratamiento de datos personales por parte de un organismo público solo podrá efectuarse respecto de las materias de su competencia y con sujeción a ese cuerpo legal, condiciones en las cuales no es necesario contar con el consentimiento del titular.

Adicionalmente y de conformidad con el artículo 10 de esa Ley, los referidos datos sensibles no pueden ser objeto de tratamiento salvo cuando la ley lo autorice, exista consentimiento del titular o sean necesarios "para la determinación u otorgamiento de beneficios de salud que correspondan a sus titulares".

Así ocurre con las fichas clínicas, las cuales, por contener datos sensibles, solo pueden ser proporcionadas sin el consentimiento de sus titulares cuando concurra alguna de las hipótesis consignadas en el antes aludido precepto, tal como ha sido precisado por esta Entidad de Control en sus dictámenes $\mathrm{N}^{\circ}$ s. 8.531 de 2001 y 71.601 de 2009”. de la Ley $\mathrm{N}^{\circ} 20.584$ de fecha 24 abril de 2012, que se remite en el artículo 12 inciso segundo a la definición de dato sensible ya señalada en el párrafo anterior (artículo 2 de letra g) de la Ley $\mathrm{N}^{\circ}$ 19.628). Además el artículo 2 inciso 3 del Reglamento sobre Fichas Clínicas $N^{\circ} 41 / 202^{17}$, dispone expresamente que la información contenida en las fichas clínicas será considerada dato sensible

3.3. Información y anotaciones subjetivas: son las apreciaciones del profesional médico inherentes a su formación y experiencia.

\section{FUNCIONES DE LA FICHA CLÍNICA}

Las funciones de la ficha clínica son de carácter sanitario, médico legal, epidemiológico y de investigación.

La función principal es la sanitaria, esto es servir de herramienta cualitativa que integre la información necesaria en el proceso médico asistencial. Y puede reflejar el modelo de relación médico paciente, esto es, paternalismo, alianza terapéutica o contractualismo.

La función médico legal da cuenta que la ficha clínica constituye también un instrumento de prevención de litigios, dado que la Ley No20.584 incorpora la mediación por daños en salud como método alternativo de resolución de conflictos. Igualmente es un medio de prueba para dirimir responsabilidades civiles, penales y administrativas $^{18}$.

17 Reglamento No 41/2012, sobre Fichas Clínicas. Diario Oficial, 15 de diciembre del 2012. Artículo 2.

${ }^{18}$ Ley $\mathrm{N}^{\circ}$ 20.584, Sobre derechos y deberes de las personas que las personas tienen en relación con acciones vinculadas con salud. Diario Oficial, 24 de abril del 2012. Artículo 3. 
La función epidemiológica significa que en caso de epidemias, es posible el acceso a la información contenida en la ficha clínica. Más aún, los profesionales del equipo de salud están obligados a informar a la autoridad sanitaria de estos $\operatorname{casos}^{19}$.

La función investigativa consiste en que la ficha clínica constituye un insumo fundamental de numerosas investigaciones científicas. Sin embargo, el acceso a la misma demanda el consentimiento del paciente que es titular del instrumento ${ }^{20}$.

\section{FUNCIÓN INVESTIGATIVA DE LA FICHA CLÍNICA EN EL ÁMBITO DEL AVANCE CIENTÍFICO.}

\subsection{Protección de los datos PeR- SONALES PROPORCIONADOS POR LA FICHA CLÍNICA PARA EFECTOS DE INVESTIGACIÓN CIENTÍFICA \\ La información contenida en la ficha} clínica de una persona, en su calidad de dato sensible, debe ser siempre protegida. Las personas que trabajan en equipos de salud, sean prestadores institucionales o prestadores individuales, públicos o privados, están obligadas a guardar secreto sobre los mismos, cuando provengan o hayan sido recolectados de fuentes no accesible al público, como asimismo sobre los demás datos $\mathrm{y}$ antecedentes relacionados con el banco de datos, obligación que no cesa por haber terminado sus actividades en ese ámbito. Lo anterior se desprende de los artículos 3

19 Ley $\mathrm{N}^{\circ} 19.628$, Sobre protección a la vida privada. Diario Oficial, 28 de agosto de 1999. Artículo 2 letra f). ${ }^{20}$ Ley $\mathrm{N}^{\circ} 19.628$, Sobre protección a la vida privada. Diario Oficial, 28 de agosto de 1999. Artículos 10 y 11 . y 9 inciso segundo de la Ley $\mathrm{N}^{\circ} 20.584^{21}$ en relación al artículo 7 de la Ley $\mathrm{N}^{\circ} 19.628^{22}$.

Para investigación científica se puede acceder a las fichas clínicas previo cumplimiento de exigencias más rigurosas determinadas por el Legislador. Así se desprende por inferencia de los artículos 10 y 11 de la Ley $\mathrm{N}^{\circ} 19.628^{23}$ sobre protección a la vida privada y 13 de la Ley $\mathrm{N}^{\circ} 20.584$ sobre derechos y deberes que tienen las personas en relación con las acciones vinculadas a su atención en salud. Esta última disposición, es la que en definitiva coincide (acoge) la opinión del Honorable Senador señor Cantuarias que data de la discusión (1995) sobre la extensión del derecho al anonimato y reserva de la información en el Primer Informe de Constitución del Proyecto de ley sobre protección civil a la vida privada señalando: "que dicho aspecto apunta, particularmente, en la dirección de que los datos de las personas que figuran en los registros de determinadas instituciones, organismos y servicios, no puedan ser dados a conocer por estos, sin autorización expresa del titular. Es decir, importa no solo una noción negativa, consistente en vedar el acceso de terceros a la vida privada, sino una activa, que refleja el control de la persona sobre la información que se refiera a hechos de su vida privada" ${ }^{24}$.

${ }^{21}$ Ley $\mathrm{N}^{\circ}$ 20.584, Sobre derechos y deberes de las personas que las personas tienen en relación con acciones vinculadas con salud. Diario Oficial, 24 de abril del 2012. Artículo 3.

22 Ley $\mathrm{N}^{\circ} 19.628$, Sobre protección a la vida privada. Diario Oficial, 28 de agosto de 1999. Artículo 2 letra f). Sobre los demás datos y antecedentes relacionados con el banco de datos, obligación que no cesa por haber terminado sus actividades en ese campo.

${ }^{23}$ Ley $\mathrm{N}^{\circ} 19.628$, Sobre protección a la vida privada. Diario Oficial, 28 de agosto de 1999. Artículos 10 y 11

24 Boletín No 896-07, Proyecto de Ley sobre protección civil a la vida privada. Senado, 17 de mayo de 1995. p. 26 
La opinión del Honorable Senador señor Canturias no predominó en su momento, considerando la Comisión que de no darse correcta aplicación a este derecho, se podría entrar en colisión con el legítimo derecho de la libertad de la información, porque hay determinados antecedentes que no deben permanecer desconocidos, sin romper el justo equilibrio entre el derecho a la privacidad que le asiste a toda persona y el hecho de que ella vive en sociedad.

Al respecto se evidencia del artículo 13 inciso tercero de la Ley $\mathrm{N}^{\circ} 20.584$ citado, que del manejo de la ficha clínica para efectos de investigación, aparecen los siguientes elementos:

- Que la ficha clínica permanecerá por un período de al menos quince años en poder del prestador, quien será responsable de la reserva de su contenido ${ }^{25}$.

- La necesidad del Reglamento 41/2012 Ministerio de Salud, publicado en el Diario Oficial con fecha 15 diciembre de 2012 que establece la forma y las condiciones bajo las cuales los prestadores almacenarán las fichas, así como las normas necesarias para su administración, adecuada protección y eliminación ${ }^{26}$.

- Los terceros que no estén directamente relacionados con la atención de salud de la persona no tendrán acceso a la información contenida en la respectiva ficha clínica. Ello incluye al personal de salud y administrativo del mismo prestador, no vinculado a

25 Reglamento No 41/2012, sobre Fichas Clínicas. Diario Oficial, 15 de diciembre del 2012. Artículo 11.

26 Reglamento No 41/2012, sobre Fichas Clínicas. Diario Oficial, 15 de diciembre del 2012. Artículo 8. la atención de la persona. Tampoco tendrán acceso a la ficha clínica los investigadores que se sirvan de estas como insumo de sus trabajos de investigación.

- Sin perjuicio de lo anterior, la información contenida en la ficha, copia de la misma o parte de ella, será entregada, total o parcialmente, a solicitud expresa de las personas y organismos que se indican a continuación, en los casos, forma y condiciones que se señalan: a) Al titular de la ficha clínica (siempre y sin condiciones), a su representante legal o, en caso de fallecimiento del titular, a sus herederos. b) A un tercero debidamente autorizado por el titular, mediante poder simple otorgado ante Notario.

Para obtener el acceso a la ficha clínica por parte del investigador, este podrá ser autorizado directamente por el titular de la ficha clínica, es decir, la persona natural a la que se refieren los datos de carácter personal ${ }^{27}$; o por el representante legal, siguiendo las reglas generales de derecho civil; o por los herederos en caso de fallecimiento del titular. La última autorización constituye una vía indirecta, a través de la cual los investigadores podrían acceder a la información contenida en la ficha clínica del sujeto de investigación.

La letra b) del articulado en comento, es la que devela una mayor aplicación, y se refiere al acceso que podría llegar a tener el investigador, en la medida que sea autorizado por el titular, mediante poder simple otor-

${ }^{27}$ Ley $\mathrm{N}^{\circ} 19.628$, Sobre protección a la vida privada. Diario Oficial, 28 de agosto de 1999. Artículo 2 letra ñ). 
gado ante Notario. La redacción es clarísima y no deja otra vía de acceso.

Se agrega como caso particularísimo para efectos de investigación, el de las personas con discapacidad psíquica o intelectual, que trata el artículo 28 de la Ley $\mathrm{N}^{\circ} 20.584$ sobre derechos y deberes que tienen las personas en relación con las acciones vinculadas a su atención en salud ${ }^{28}$, que distingue entre las que pueden expresar su voluntad y aquellas que no pueden expresar su voluntad para participar en una investigación científica. En el primer caso, existe posibilidad de acceder a los datos contenidos en la ficha clínica de la persona con discapacidad psíquica o intelectual por parte del investigador, en la medida que hayan prestado su consentimiento informado, haya sido evaluado el proyecto por el comité ético científico que corresponda y exista autorización sanitaria de la autoridad competente; en el segundo caso, existe prohibición de participación de la persona discapacitada psíquica o intelectualmente en la investigación científica, motivo por el cual nunca un investigador podrá acceder a la información contenida en la ficha clínica.

El investigador que no cuenta con las autorizaciones correspondientes puede ser sancionado de acuerdo con lo dispuesto en el artículo 20 de la Ley $\mathrm{N}^{\circ} 20.120^{29}$, con suspensión por tres años del ejercicio profesional y con la prohibición absoluta de ejercicio profesional en el territorio nacional en

\footnotetext{
${ }^{28}$ Ley $N^{\circ} 20.584$, Sobre derechos y deberes que las personas tienen en relación con acciones vinculadas con salud. Diario Oficial, 24 de abril del 2012. Artículo 28.

29 Ley $\mathrm{N}^{\circ}$ 20.120, Sobre investigación científica en el ser humano, su genoma y prohíbe la clonación humana. Diario Oficial, 22 de septiembre de 2006. Artículo 20.
}

caso de reincidencia. La Ley $\mathrm{N}^{\circ} 20.584$ que regula los derechos y deberes que tienen las personas en relación con las acciones vinculadas a su atención en salud, no trata directamente este punto, solo se refiere a eventuales reclamos y sanciones a las que están sujetas los prestadores institucionales e individuales.

El investigador también puede acceder a la ficha clínica a través de la autoridad sanitaria. Ello deriva de la historia fidedigna de la Ley $\mathrm{N}^{\circ} 20.584$ sobre derechos y deberes que tienen las personas en relación con las acciones vinculadas a su atención en salud, que la Cámara aprobó una redacción diversa a la definitiva del artículo 13 inciso tercero letra d) que indicaba lo siguiente: "Sin perjuicio de lo anterior, la información contenida en la ficha podrá ser entregada, total o parcialmente, a solicitud expresa de las personas y organismos que se indican a continuación, en los casos, forma y condiciones que se señalan:

d) Al Ministerio de Salud, a las Secretarías Regionales Ministeriales de Salud, a la Superintendencia de Salud, a los Servicios de Salud, al Instituto de Salud Pública y al Fondo Nacional de Salud, en los casos en que los datos sean necesarios para estudios estadísticos, de seguimiento, de salud pública, de fiscalización o para resolver acerca de la procedencia de determinados beneficios de salud o seguridad social. Para dichos efectos podrán solicitar informes sobre el contenido de la ficha, así como copia de toda o parte de ella. En caso que las conclusiones o resultados sean divulgados, el tratamiento de la información emanada de las fichas deberá garantizar que esta no pueda asociarse a persona determinada o determinable.

Los demás organismos públicos y privados que se encuentren facultados por ley para fiscalizar o para resolver acerca de la procedencia de determinados beneficios 
de salud o seguridad social, podrán solicitar un informe sobre aspectos específicos de la ficha clínica.

Las personas y los organismos a que se refieren los incisos tercero y cuarto serán responsables de mantener la confidencialidad del contenido de la ficha y de la identidad de su titular, así como también de utilizar la información que de ella emana exclusivamente para los fines requeridos.

Sin perjuicio de lo indicado en los dos incisos anteriores, cuando por razones de investigación científica o epidemiológica, terceros ajenos a la atención de salud sean autorizados por el prestador para acceder al contenido de la ficha, se deberá asegurar la debida protección de la confidencialidad de la información de salud a que tengan acceso" 30 .

Esta norma fue eliminada en el Senado, en el Informe de Comisiones Unidas, durante el Segundo Trámite Constitucional, por observación del Honorable Senador señor Patricio Walker, que advirtió que los Organismos públicos que necesitan esta información de acceso a la ficha clínica con fines estadísticos, de fiscalización o salud pública, ya están autorizados por el Decreto con Fuerza del Ley No 1 del Ministerio de Salud, de 2005 en su artículo 4 numerando 5 , a modo de ejemplo ${ }^{31}$. Por lo demás, dicha

\footnotetext{
30 Boletín No 4398-11, Proyecto de Ley que regula los derechos y deberes que las personas tienen en relación con acciones vinculadas con salud. Cámara de Diputados, 29 de noviembre de 2011. pp. 827-830.

31 Boletín No 4398-11, Proyecto de Ley que regula los derechos y deberes que las personas tienen en relación con acciones vinculadas con salud. Senado, $22 \mathrm{de}$ agosto de 2011. p. 718 .

Decreto Ley No 1, Fija texto refundido, sistematizado y coordinado del DL No 2.763, de 1979 y de las Leyes No 18.933 y No 18.469., de 2005 Subsecretaría de Salud Pública de 23 de septiembre de 2005. Diario Oficial, 24 de abril de 2006). Artículo 4.
}

norma citada por el Honorable Senador señor Walker, coincide (reproduce) el artículo 4 número 5 de la Ley 19.937 que modifica el D.L. No 2.763, de 1979, con la finalidad de establecer una nueva concepción de la autoridad sanitaria, distintas modalidades de gestión y fortalecer la participación ciudada$\mathrm{na}^{32}$. Ambas normas, en el artículo 4 número 5 señalan:

"Al Ministerio de Salud le corresponderá formular, fijar y controlar las políticas de salud. En consecuencia tendrá, entre otras, las siguientes funciones:

5.- Tratar datos con fines estadísticos y mantener registros o bancos de datos respecto de las materias de su competencia. Tratar datos personales o sensibles con el fin de proteger la salud de la población o para la determinación y otorgamiento de beneficios de salud. Para los efectos previstos en este número, podrá requerir de las personas naturales o jurídicas, públicas o privadas, la información que fuere necesaria. Todo ello conforme a las normas de la ley $\mathrm{N}^{\circ} 19.628$ y sobre secreto profesional".

En directa relación al tratamiento de datos estadísticos, el artículo 20 de la Ley $\mathrm{N}^{\circ} 19.628$ dispone que no es necesario el consentimiento del titular en el tratamiento de datos personales, cuando un organismo público competente actúa de acuerdo a la normativa precedente (se refiere a los artículos 1 a 19 del mismo cuerpo legal) ${ }^{33}$.

\footnotetext{
32 Ley $\mathrm{N}^{\circ}$ 19.937, Modifica el DL No 2.763, de 1979 , con la finalidad de establecer una nueva concepción de la autoridad sanitaria, distintas modalidades de gestión y fortalecer la participación ciudadana. Diario Oficial 24 de febrero 2004. Artículo 4.

33 Ley N ${ }^{\circ} 19.628$, Sobre protección a la vida privada. Diario Oficial, 28 de agosto de 1999. Artículo 20.
} 
Por su parte el Ministro de Salud en su Oficio Ord. No A15 3392, 29 de octubre de $2012^{34}$, explicita la interpretación anterior en los siguientes términos: "Ahora bien, como puede advertirse, esta disposición busca evitar la intromisión de terceros no vinculados al proceso de entrega de prestaciones en las fichas clínicas, sin embargo, no puede tener efectos sobre otras normas legales que autorizan a determinados funcionarios o entidades el estudio de fichas clínicas para la determinación de entrega de acciones de salud o la fiscalización y auditoría de aquellas ya otorgadas, todo ello sujeto a la obligación de guardar la reserva de su contenido que le impone su calidad de datos sensibles.

Es así que el artículo $4^{\circ}$ del DFL $\mathrm{N}^{\circ} 1$ de 2005, de este Ministerio, en su numeral $5^{\circ}$, le confiere la facultad de tratar datos con fines estadísticos y mantener registros o bancos de datos respecto de las materias de competencia, así como tratar datos personales o sensibles con el fin de proteger la salud de la población, para la determinación y otorgamiento de beneficios de salud, señalando al efecto: "Para los efectos previstos en este número, podrá requerir de las personas naturales o jurídicas, públicas o privadas, la información que fuere necesaria. Todo ello conforme a las normas de la ley $\mathrm{N}^{\circ} 19.628$ y sobre secreto profesional”.

La primera de las nombradas está referida a la ley $\mathrm{N}^{\circ} 19.628$ sobre protección a la vida privada $y$, en el segundo caso, la referencia debe entenderse formulada al artículo 247 del Código Penal, que prohíbe a los funcionarios públicos descubrir los secretos de un particular en su perjuicio, al igual que prohíbe a quienes ejercen alguna

\footnotetext{
34 Oficio Ord. NoA15 3392, 29 de octubre de 2012, Ministerio de Salud. Párrafos segundos, tercero, cuarto y quinto.
}

de las profesiones que requieren título, revelen los secretos que por razón de ella se les hubieren confiado.

Igualmente, normas como la del artículo 47 del Código Sanitario, permiten la recolección de datos estadísticos cuyo conocimiento tiene importancia para la protección, fomento y recuperación de la salud, así como la facultad que entrega el artículo 10 de la ley $\mathrm{N}^{\circ} 19.628$ para el tratamiento de datos sensibles -característica que poseen los estados de salud- necesarios para la determinación u otorgamiento de beneficios de salud que correspondan a sus titulares, consideramos que también mantienen su vigencia y aplicación bajo el imperio de la ley de derechos y deberes.

A lo anterior deben agregarse las facultades de fiscalización que por ley están conferidas a otros organismos del sector salud:

5.1. Así es preciso destacar las que se confieren a la Superintendencia de Salud los artículos $110 \mathrm{~N}^{\circ} 4,115 \mathrm{~N}^{\circ} 7,121$ $\mathrm{N}^{\circ} \mathrm{s} 4$ y 11 y aquellas consideradas en los artículos $110 \mathrm{~N}^{\circ} 17,115 \mathrm{~N}^{\circ} 6$; $121 \mathrm{~N}^{\text {os }} 10 \mathrm{y}$ 11 y 189 todos del DFL $N^{\circ} 1$, de 2005, de este Ministerio cuando cumplan las labores de fiscalización que la propia ley 20.584 le asigna en sus artículos 38 y 37 relativos al cumplimiento de sus normas. Pueden señalarse, además, las funciones fiscalizadoras de tal Intendencia de Prestadores, respecto de las entidades acreditadas, de acuerdo con el artículo $121 \mathrm{~N}^{\circ} 4$ de ese DFL.

5.2. Del mismo modo queda comprendido en esta prerrogativa el ejercicio, de las facultades de fiscalización por parte del Fondo Nacional de Salud conforme al artículo 50 de dicho texto, para verificar que el financiamiento que efectúe corresponda a las prestaciones otorgadas al beneficiario. 
5.3. En el mismo ámbito se encuentran aquellas asignadas a las ISAPRE para el otorgamiento de beneficios de salud según lo dispuesto en los artículos 189 de dicho DFL y 10 de la ley No 19.628 ".

\subsection{Consentimiento del sujeto de INVESTIGACIÓN}

La Ley $\mathrm{N}^{\circ} 20.120$, sobre Investigación científica en el ser humano, su genoma y prohíbe la clonación humana ${ }^{35}$, consagra en su artículo 2 como principio rector la libertad para llevar a cabo las investigaciones científicas biomédicas en seres humanos tiene como límite el respeto a los derechos y libertades esenciales que emanan de la naturaleza humana, reconocidos tanto por la CPR como por los Tratados Internacionales ratificados por Chile y que se encuentran vigentes.

En directa relación a lo señalado, el artículo 11 de la Ley $\mathrm{N}^{\circ} 20.120$, sobre investigación científica en el ser humano, su genoma y prohíbe la clonación humana prescribe:

"Toda investigación científica en un ser humano deberá contar con su consentimiento previo, expreso, libre e informado, o, en su defecto, el de aquel que deba suplir su voluntad en conformidad con la ley.

Para los efectos de esta ley, existe consentimiento informado cuando la persona que debe prestarlo conoce los aspectos esenciales de la investigación, en especial su finalidad, beneficios, riesgos y los procedimientos o tratamientos alternativos. Para ello deberá habérsele proporcionado información adecuada, suficiente y comprensible sobre ella.

35 Ley $\mathrm{N}^{\circ}$ 20.120, Sobre investigación científica en el ser humano, su genoma y prohíbe la clonación humana. Diario Oficial, 22 de septiembre de 2006. Artículos 2 y 11 .
El consentimiento deberá constar en un acta firmada por la persona que ha de consentir en la investigación, por el director responsable de ella y por el director del centro o establecimiento donde ella se llevará a cabo, quien, además, actuará como ministro de fe".

\section{a. Especificidad del consentimiento del sujeto de investigación}

Para cada investigación se requiere el consentimiento previo y determinado del sujeto que participará en el estudio. Es más el consentimiento deberá ser nuevamente solicitado cada vez que los términos o condiciones en que se desarrolle la investigación sufran modificaciones, salvo que estas sean consideradas menores por el Comité Ético Científico que haya aprobado el proyecto de investigación.

\section{b. Revocabilidad del consentimiento del sujeto de investigación}

En cualquier momento y por cualquier medio, el sujeto que participe en la investigación tiene derecho de revocar su consentimiento y dejar de participar, sin que ello importe responsabilidad, sanción o pérdida de beneficio alguno.

c. Decisiones por otros, en materia de consentimiento del sujeto de investigación

i. Situación de las personas con discapacidad psíquica o intelectual.

Según el artículo 28 de la Ley $\mathrm{N}^{\circ}$ $20.584^{36}$ : Ninguna persona con discapacidad psíquica o intelectual que no

36 Ley $N^{\circ}$ 20.584, Sobre derechos y deberes de las personas que las personas tienen en relación con acciones vinculadas con salud. Diario Oficial, 24 de abril del 2012. Artículo 28. 
pueda expresar su voluntad podrá participar en una investigación científica. La normativa aludida opta por prohibición taxativa. Por tanto, solamente se podrá realizar investigación científica con participación de personas con discapacidad psíquica o intelectual que tengan la capacidad de manifestar su voluntad y que hayan dado consentimiento informado. Además se requerirá la manifestación de voluntad del representante de la persona con discapacidad psíquica o intelectual; la evaluación ético científica que corresponda y, la autorización de la Autoridad Sanitaria competente. En contra de las actuaciones de los prestadores y la Autoridad Sanitaria en relación a investigación científica, podrá presentarse un reclamo a la Comisión Regional que corresponda, a fin de que esta revise los procedimientos en cuestión.

ii. Situación de los niños, niñas y adolescentes menores de 18 años.

Los padres o quienes por mandato legal tengan a su cargo el cuidado de los niños, niñas o adolescentes menores de 18 años, pueden autorizar la participación de estos de acuerdo a las reglas generales de representación contenidas en el Código Civil. El Legislador en las Leyes $\mathrm{N}^{\circ} 20.120 \mathrm{y}$ $\mathrm{N}^{\circ} 20.584$, no contempla la anuencia del menor de edad para participar como sujeto de investigación científica ni tampoco en lo referente a su atención de salud ni en el manejo de la información sensible que contiene su ficha clínica, y ni siquiera cuando existen grados de competencia para tomar decisiones autónomas, de acuerdo a la edad y madurez del mismo $^{37}$.

\section{PROPIEDAD}

Destaca en el Mensaje de la Ley $\mathrm{N}^{\circ}$ 20.584, que en forma explícita se indica bajo el epígrafe "Confidencialidad de la información de salud" lo siguiente: "Más que discutir de a quién le corresponde la propiedad de la materialidad de la ficha clínica, lo relevante es garantizar su resguardo por los prestadores y, al mismo tiempo, el régimen restringido bajo el cual terceros, no relacionados con la atención de salud, pueden tener conocimiento de la información de salud de una persona" 38 .

37 Vivanco, Ángela (2009): "Negativa de un menor de edad y de su familia a que este reciba una terapia desproporcionada". Revista Chilena de Derecho, vol. 36 No 2: pp. 399-440.

Se estima necesario considerar la anuencia, al menos del menor adulto como sujeto de investigación y en las atenciones de salud que reciba. Los criterios de capacidad civil aplicados a las decisiones en salud resultan insatisfactorios como entre otros, plantea la profesora Ángela Vivanco Martínez.

38 Boletín No 4398-11, Proyecto de Ley que regula los derechos y deberes que las personas tienen en relación con acciones vinculadas con salud. Cámara de Diputados, 26 de julio de 2006. p. 10.

Señala en relación a la propiedad de la ficha clínica: "el representante del Ejecutivo aclaró que en esta iniciativa legal se pretendió obviar el debate que surgió con ocasión del proyecto de ley sobre derechos u deberes de las personas en salud, contenido en el boletín $\mathrm{N}^{\circ}$ 2727-11 que fue archivado, en una de cuyas normas se establecía que la ficha era de propiedad del paciente. Indicó que se optó por establecer un régimen de acceso y de protección de la confidencialidad en lugar de abordar el tema de la propiedad de la ficha, dado que ni el prestador ni el paciente pueden ejercer los atributos del dominio respecto de este instrumento, régimen en el cual se distingue entre los datos que contiene la ficha, que pertenecen al paciente y la custodia de esta última, que corresponde al prestador". 
6.1. INFORMACIÓN DEL CONTENIDO DE LA FICHA CLÍNICA

\section{a. Materialidad del instrumento}

La ficha clínica permanecerá por un período de al menos quince años en poder del prestador, quien será responsable de la reserva de su contenido. Un reglamento expedido a través del Ministerio de Salud establecerá la forma y las condiciones bajo las cuales los prestadores almacenarán las fichas, así como las normas necesarias para su administración, adecuada protección y eliminación, según lo dispuesto en el artículo 13 de la Ley $\mathrm{N}^{\circ} 20.584$.

\section{b. Responsabilidad}

Las instituciones y personas indicadas adoptarán las providencias necesarias para asegurar la reserva de la identidad del titular de las fichas clínicas a las que accedan, de los datos médicos, genéticos u otros de carácter sensible contenidos en ellas y para que toda esta información sea utilizada exclusivamente para los fines requeridos, según lo dispuesto en el artículo 13 de la Ley $\mathrm{N}^{\circ} 20.584$.

Las sanciones que contempla el cuerpo normativo, se consagran en el artículo 38 de la Ley $\mathrm{N}^{\circ} 20.584$, y atienden principalmente a la responsabilidad administrativa de los funcionarios mediante procedimientos administrativos o procesos de calificación correspondientes.

\section{ACCESO}

El Mensaje de la Ley $\mathrm{N}^{\circ} 20.584$, considera en su artículo 13 número 1 , la facultad del médico de restringir la información de la ficha clínica al titular de la misma atendido el estado emocional, psiquiátrico o psicológico del paciente que considere in- conveniente; en el número 2 , se indica que tanto representantes legales, como herederos o un tercero debidamente autorizado, pueden acceder a la información que contiene la ficha; el numerando 3, autoriza el acceso a la ficha clínica a variadas instituciones y; el numerando 4, además de aludir a la autoridad sanitaria, considera que terceros ajenos a la atención de salud puedan ser autorizados por el prestador para acceder al contenido de la ficha clínica por razones de investigación cientifica o epidemiológica ${ }^{39}$. Las facultades enunciadas, fueron modificadas en los diferentes trámites del proceso legislativo y en definitiva en la Ley no se consideraron.

\subsection{Titular/ Representante Legal/ HEREDEROS}

Se remite a la información trabajada en el punto número IV. 1 bajo el título: Protección de los datos personales proporcionados por la ficha clínica para efectos de investigación científica, del presente documento.

A lo anterior, se agrega que el artículo 23 de la Ley $N^{\circ} 20.584$ autoriza al profesional tratante para restringir justificadamente el acceso a la información contenida en la ficha clínica, al titular de la misma en caso que pueda generar efectos negativos para su estado mental ${ }^{40}$.

\subsection{Servicios de Salud}

Se remite a la información trabajada en el punto número III, número 3 bajo el título: Funciones de la ficha clínica, 3.

\footnotetext{
39 Boletín No 4398-11, Proyecto de Ley que regula los derechos y deberes que las personas tienen en relación con acciones vinculadas con salud. Cámara de Diputados, 26 de julio de 2006. pp. 23 y 24.

${ }^{40}$ Ley $\mathrm{N}^{\circ}$ 20.584, Sobre derechos y deberes de las personas que las personas tienen en relación con acciones vinculadas con salud. Diario Oficial, 24 de abril del 2012. Artículo 23.
} 
Función epidemiológica y específicamente la nota al pie número 13 , del presente documento.

\subsection{Circuito Judicial.}

Sin perjuicio de la restricción general que establece el artículo 13 de la Ley $\mathrm{N}^{\circ} 20.584$ para el acceso a la información contenida en la ficha, se sostiene que copia de la misma o parte de ella, será entregada, total o parcialmente, en la forma y condiciones que se señalan, a solicitud expresa de las personas y organismos siguientes: Tribunales de Justicia, siempre que la información contenida en la ficha clínica se relacione con las causas que estuvieren conociendo y; fiscales del Ministerio Público o abogados, previa autorización del juez competente, cuando la información se vincule directamente con las investigaciones o defensas que tenga. Las instituciones y personas indicadas precedentemente adoptarán las providencias necesarias para asegurar la reserva de la identidad del titular las fichas clínicas a las que accedan, de los datos médicos, genéticos u otros de carácter sensible contenidos en ellas y para que toda esta información sea utilizada exclusivamente para los fines para los cuales fue requerida ${ }^{41}$.

\section{COMENTARIOS FINALES}

1. El Legislador define la ficha clínica como el "instrumento obligatorio en el que se registra el conjunto de antecedentes relativos a las diferentes áreas relacionadas con la salud de las personas...", artículo 12 de la Ley $\mathrm{N}^{\circ}$ 20.584. Además exige que la información consignada en este instrumento

${ }^{41}$ Ley $\mathrm{N}^{\circ} 20.584$, Sobre derechos y deberes que las personas tienen en relación con acciones vinculadas con salud. Diario Oficial, 24 de abril del 2012. Artículo 13, específicamente letras c), d) y párrafo final. refleje claridad, veracidad, sistematicidad, pertinencia, que sea completa y sus registros sean oportunos y bien resguardados.

2. Se observa que la ficha clínica considera datos de carácter personal, sensible y apreciaciones preliminares del profesional médico. Al respecto, la Ley $\mathrm{N}^{\circ} 20.584$, califica la información que surge de la atención de salud como dato sensible de acuerdo a lo establecido en la Ley 19.628 sobre protección a la vida privada. Estos "datos sensibles" no pueden ser objeto de tratamiento, salvo que la ley lo autorice, exista consentimiento del titular o sea necesario para el otorgamiento de beneficios de salud a los titulares. Se entiende por tratamiento, cualquier operación o complejo de operaciones o procesos técnicos que signifiquen utilizarlos en cualquier forma por ejemplo como insumo para investigaciones.

3. Respecto al titular de la ficha clínica, este corresponde a la persona natural a la que se refieren los datos de carácter personal, por aplicación del artículo 2 letra ñ) de la Ley 19.628 sobre protección a la vida privada $^{42}$.

En el caso de la representación legal y de la competencia se siguen las reglas generales propias del Derecho Civil las que resultan insatisfactorias en lo referente a las decisiones en salud. Así por ejemplo, en Chile se desconoce al menor el derecho a la autonomía gradual -asentimiento- en atención a su edad y madurez que consagra el artículo 12 de la Convención de los Derechos del $\mathrm{Niño}^{43}$-ratificada por Chile- en los siguientes términos:

\footnotetext{
42 Ley $\mathrm{N}^{\circ} 19.628$, Sobre protección a la vida privada. Diario Oficial. Señala artículo 2 letra ñ).

43 Decreto No 830 de 18 de agosto de 1989, que
} 
"Los Estados parte garantizarán al niño que esté en condiciones de formarse un juicio propio el derecho de expresar su opinión libremente en todos los asuntos que afectan al niño, teniéndose debidamente en cuenta las opiniones del niño, en función de la edad y madurez del niño". Las reglas del Código Civil tampoco responden a la declinación gradual de la autonomía del adulto mayor. En suma, no se hace cargo del desarrollo y declinación de la autonomía de toda persona. Por ello, es necesario diseñar un estatuto jurídico de la capacidad que considere la competencia -autonomíaen términos más amplios.

4. En relación al régimen de acceso la Ley $\mathrm{N}^{\circ} 20.584$ establece el criterio general de protección de la confidencialidad de la información contenida en la ficha clínica. Solo determinadas personas están habilitadas para acceder a esa información: los relacionados directamente con la atención de salud del paciente. Y acto seguido, regula de manera pormenorizada las situaciones en que es finalmente necesario permitir que esta confidencialidad ceda en cada caso particular y bajo estrictas normas sobre su manejo. La restricción en el acceso puede ser total o parcial. La información solo debe ser usada exclusivamente para los fines con que fue requerida.

Según la Ley $N^{\circ} 20.584$, el titular de la ficha clínica está habilitado siempre para solicitar su ficha clínica (no necesita estar involucrado en un juicio ni justificar su solicitud). Lo puede hacer directamente, su representante legal o por tercero debidamente autorizado mediante poder simple ante Notario. En caso de fallecimiento pue-

promulga Convención Internacional de los Derechos del Niño. Diario Oficial, 27 de septiembre de 1990. den acceder sus herederos. Al respecto, es contradictorio que por una parte se proteja con celo la información sensible registrada en una ficha clínica, la cual incluso el titular intencionalmente reservó del conocimiento a su familia y por otra parte, al momento de su muerte por ese solo hecho dicha información es accesible a los herederos quien generalmente es su familia. El acceso a esta información sensible por los herederos puede ocasionar daños a estos y a la memoria del causante.

Por su parte, los Tribunales de justicia como los Fiscales del Ministerio Público y los abogados defensores pueden acceder a la ficha clínica de acuerdo a los siguientes supuestos: que exista un juicio, que el tribunal lo solicite; que la información contenida en la ficha se relacione con quien tenga el carácter de parte o imputado. El único caso en que el profesional tratante puede limitar el acceso del titular a su ficha es si dicha información pudiera tener un efecto negativo en su estado mental, según lo dispuesto en el artículo 23 de la Ley $N^{\circ} 20.584$.

Las personas autorizadas para acceder a esa ficha son responsables de mantener la confidencialidad de su contenido y la identidad del titular de la ficha, reservando la información que contiene exclusivamente al uso para el cual se permite su conocimiento.

Con todo el Legislador faculta a la Administración (Ministerio de Salud, Servicios de Salud, Instituto de Salud Pública) para acceder a la información de la ficha clínica para fines estadísticos; de fiscalización o de salud pública según lo dispuesto en el artículo 4 número 5 del DFL $\mathrm{N}^{\circ} 1$ de Salud del año 2005. Se entiende que la Administración y sus diferentes órganos en el ejercicio de sus funciones respetan los derechos y libertades esenciales que emanan de la naturaleza humana y excepcional- 
mente afectan en forma parcial y limitada el ejercicio de esos derechos, en este caso la privacidad de la información que consta en la ficha clínica- en pos del bien de la comunidad. El prestador de salud en estos casos podrá entregar información limitada solo a esos fines ${ }^{44}$.

5. Existen diferentes tipos de investigaciones científicas en el ámbito de las ciencias biomédicas y sociales: histórica, documental, descriptiva, correccional, explicativa, estudio de casos, seccional, longitudinal o experimental; y ello debería generar diferenciaciones en la protección de los datos sensibles, seccionando la información contenida en la ficha clínica, para efectos de dar acceso a los investigadores.

De este modo se daría aplicación concreta a la Ley $\mathrm{N}^{\circ} 19.628$, sobre aspectos contenidos concretamente en la ficha clínica. El artículo 2 letra l) de dicho cuerpo

44 Circular 15/15 de 18 de abril de 2013, Sobre Emisión de consentimiento de personas participantes de una investigación científica. Ministerio de Salud. En ella, la autoridad postula una interpretación extensiva en el penúltimo párrafo: "De acuerdo con lo expuesto, por tratarse de una ley específico sobre la materia, como es la investigación científica, sus disposiciones tienen preeminencia en estos casos por sobre las de la ley No 20.584, sobre derechos y deberes de las personas en su atención en salud, y, por ello, no se requiere que el consentimiento en referencia se otorgue ante notario, como establece la ley No 20.584, en su artículo 13 letra b) para el acceso a las respectivas fichas clínicas, si este acceso está incluido en el acta de consentimiento descrito previamente".

No obstante la opinión de la autoridad, es necesaria la modificación del cuerpo normativo si lo que se busca es la interpretación extensiva de la Ley No 20.584 en cuanto acceso a la ficha clínica para investigación científica; el estudio riguroso de los elementos de interpretación jurídica, sean gramatical, histórico, sistemático, lógico, teleológico y axiológico, concluyen una protección firme del derecho a la privacidad e intimidad, también en el acceso de la ficha clínica para efectos científicos. legal, señala como procedimiento de disociación de datos, a todo tratamiento de datos personales de manera que la información que se obtenga no pueda asociarse a persona determinada o determinable. Según dicha disposición para efectos de investigación, la ficha clínica siempre está amparada por el secreto estadístico.

6. Se destaca que la Ley $\mathrm{N}^{\circ} 20.584$ restringe el acceso a la ficha clínica respondiendo a un nuevo paradigma cultural en cuanto al tratamiento del paciente, a su entorno y respeto durante su ciclo vital. Es una manifestación visible que la persona es un fin en sí misma y no medio para otros fines, aunque se presenten loables como el avance de las Ciencias.

7. Por su parte la Autoridad Sanitaria a través del Oficio Ord. No A15 3392 de 29 octubre de 2012 del Ministerio de Salud $^{45}$ y del Reglamento sobre Fichas Clí-

45 Oficio Ord. NoA15 3392, 29 de octubre de 2012, Ministerio de Salud. En este mismo sentido se pronuncia en el párrafo $6^{\circ}$ : "La situación expuesta, se espera que quedará perfectamente aclarada una vez que entre en vigencia el reglamento sobre fichas clínicas, que se encuentra en etapa de formalización, en el cual se reconoce la vigencia de las normas específicas que poseen determinadas entidades para revisar o estudiar fichas clínicas con fines de fiscalización de las prestaciones entregadas, de determinación de beneficios de salud a las personas o de protección de la salud de la población, materia que además fue recogida en la historia fidedigna del establecimiento de la ley 20.584". Párrafo $7{ }^{\circ}$. "Sin perjuicio de lo señalado y con el ánimo de que las importantes labores descritas que con los fines antes señalados se llevan a cabo en los organismos del sector salud, no se vean entorpecidas por no contar los funcionarios a cargo con acceso a la información contenida en las fichas clínicas necesarias, se emiten las presentes precisiones con el ánimo de colaborar en el desarrollo regular de la función pública que estos organismos, sin perjuicio de reiterarse que todos aquellos que tomen conocimiento de esta información quedan obligados a guardar reserva 
nicas 41/2012 (ya citado) consciente de las restricciones impuestas por ley al acceso de las mismas, reitera que se encuentran vigentes sus potestades para acceder directamente a las fichas clínicas con objetivos determinados que apuntan al bien común.

8. Del contexto de la Ley $\mathrm{N}^{\circ}$ $20.120^{46}$ y de la Ley $N^{\circ} 20.584$, es posible argumentar que la aplicación del artículo $4^{\circ}$ número 5 de la Ley 19.937 busca fomentar y promover el desarrollo en Chile de la investigación por "necesidad" frente a la que se puede calificar como por "curiosidad intelectual", a través de la elaboración de una agenda nacional de investigación a cargo del Ministerio de Salud.

9. Por último, llama la atención que la historia fidedigna de la Ley $\mathrm{N}^{\circ} 20.584$ no registra las voces de expertos en investigación, en un tema tan relevante como es el uso para investigación de las fichas clínicas.

sobre los datos que conocieron conforme exige la ley No 19.628 , sujetos a las responsabilidades legales que dicha normativa ha contemplado".

46 Boletín No 1993-11. Proyecto de Ley sobre la investigación científica en el ser humano, su genoma, y prohíbe la clonación humana. Senado, 11 de julio de 2000. pp. 46-47. 
